\title{
APPLICATION OF VATS IN DIAGNOSIS AND TREATMENT OF LUNG CANCER COMPLICATED WITH PNEUMOTHORAX
}

\author{
APLICAÇÃO DE VATS NO DIAGNÓSTICO E TRATAMENTO DE CÂNCER DE PULMÃO \\ COMPLICADO COM PNEUMOTÓRAX
}

\author{
Bin LV ${ }^{1}$; Nana ZHAO ${ }^{1}$; Li ZHANG2; Lu LIU ${ }^{1}$ \\ 1. Cardio-Thoracic Surgery of Yidu Central Hospital of Weifang, Qingzhou, 262500, China; 2. Joint Trauma Surgery of Yidu Central \\ Hospital of Weifang, Qingzhou, 262500, China.
}

\begin{abstract}
The paper aims to explore clinical symptoms and complication characteristic of lung cancer complicated with pneumothorax, analyze clinical diagnostic value of VATS, and elaborate on specific clinical programs and significance. To investigate diagnosis and therapeutic value of VATS for lung cancer complicated with pneumothorax, 1900 cases of patients with lung cancer complicated with pneumothorax were randomly selected as research objects to be treated with VATS, and then analysis of their clinical data was done. The clinical data showed that many patients were not clearly diagnosed before operation. In VATS operation, lung tumor tissue was removed and then immediately frozen and sliced. Appropriate surgical approach was chosen based on specific circumstances of patients. As can be known from the results, 1000 cases were treated with wedge resection of lung tumor under thoracoscopy, 900 cases were treated with assisted small incision surgery under thoracoscopy. 1400 cases of lung metastasis were treated with pleural friction fixation. All the operations were successful, with pathology being clearly diagnosed. After surgery, 8 patients had mild air leakage, which could be heal without special treatment. There was no perioperative death. The above analysis shows that VATS can clearly diagnose peripheral lung tumor, and fundamentally cure pneumothorax and lung cancer, which is thus recommended in clinic.
\end{abstract}

KEYWORDS: VATS. Lung Cancer Complicated with Pneumothorax. Clinical Diagnosis and Treatment.

\section{INTRODUCTION}

According to the current situation, lung cancer complicated with pneumothorax is extremely rare in clinic, while the most common disease is lung metastasis in osteosarcoma (see Figure 1). Conservative treatment is basically adopted in clinic for the above disease. However, according to analysis results of past cases, there are some flaws in conservative treatment, such as high recurrence of pneumothorax that affects prognostic effect and reduces patients' quality of life (ZHANG et al., 2011; YE et al., 2012) . According to the existing data analysis, there is no clear final conclusion for spontaneous pneumothorax pathology of lung cancer patients. But through VATS, pathogenesis of patients' spontaneous pneumothorax can be inferred, which provides reference and suggestion for clinical treatment in improving patients' prognostic outcomes and quality of life.

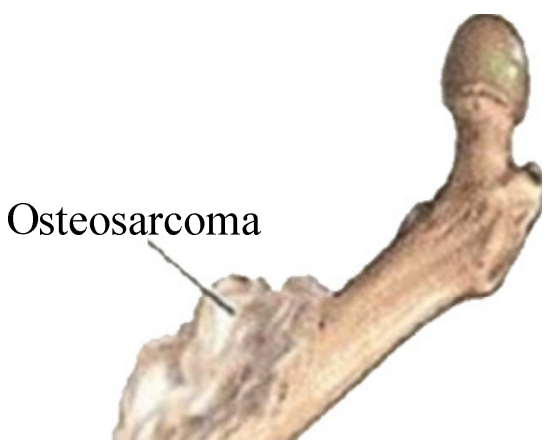

Figure 1. Schematic diagram of osteosarcoma

To explore pathogenesis of lung cancer complicated with pneumothorax and its treatment program, this paper elaborated on actual clinical application effect of VATS, with relatively satisfactory efficacy achieved, specifically as follows:

\section{MATERIAL AND METHODS}

\section{General information}

In this study, 1900 lung cancer patients complicated with spontaneous pneumothorax who 
were treated with VATS in a hospital during February 2010 and April 2016 were selected as research objects, including 1200 male patients and 700 female patients. The patients were aged between $16-71$ years, with average age at (36.5 \pm 2.0) years. Among them, there were 1300 patients with cough and chest tightness. All selected patients underwent chest CT diagnosis. Diagnostic results were unilateral peripheral lung cancer complicated with ipsilateral pneumothorax, without obvious hilar and mediastinal lymph node enlargement. The inclusion criteria of this study are as follows: based on chest CT examination, unilateral peripheral maximum diameter $\leq 5 \mathrm{~cm}$, showing signs of lung cancer complicated with ipsilateral pneumothorax, number of lung tumors $\leq 5$; all the patients had no history of spontaneous pneumothorax nor other lesions, without pathological diagnosis.

\section{Examination Method}

In this study, the method called "one-lung ventilation through double-lumen endotracheal intubation" (see Figure 2) was applied, and then the
ZHENG, F. et al

anesthetist was told to minimize air pressure. Patients were told to take standard lateral position, with waist padded. During the operation, make an $1.0-1.5 \mathrm{~cm}$ incision between the seventh or eighth rib as a viewport. After one-lung ventilation, progressive examination was needed. Then according to the conditions of affected site, make primary incision $(2.5-5 \mathrm{~cm})$ by virtue of laparoscopy between the fifth or sixth rib. During the operation, intrathoracic adhesion should be separated, patient's lesions should be comprehensively searched in detail to understand patient's pleural condition. Then remove surface lung tumor by means of electric knife, and apply pathology frozen section during surgery. For patients with lung metastasis, parietal pleura friction can be implemented by virtue of gauze ball, and then have the pleura fixed. Finally, flush with saline, and check if there is air leakage during chest examination. Intrathoracic drain should be placed in the viewport to connect drainage bottle. If there is no abnormality 1-3 days after surgery, intrathoracic drain can be pulled out (WANG et al., 2013; HUANG et al., 2013).

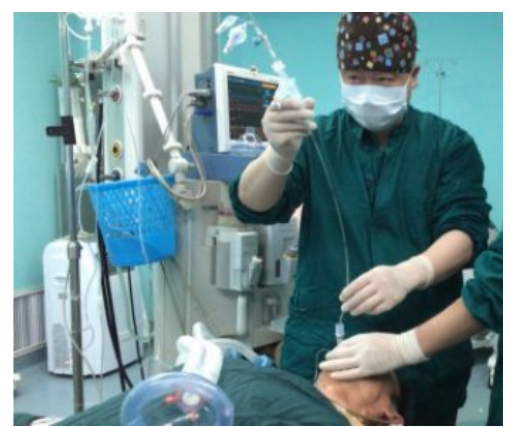

Figure 2. One-lung ventilation through double-lumen endotracheal intubation

\section{RESULTS}

During the surgery, 40 patients were proved to be with primary lung adenocarcinoma. Pulmonary lobectomy was done with VATS by small incision, accompanied with lymph node dissection; 30 patients showed lung adenocarcinoma metastasis, and 10 patients showed small cell lung cancer metastasis (see Figure 3). Due to deep focus, VATS assisted small incision radiofrequency ablation of lung tumor should be applied, to be followed with suture at the air leakage, with fibrin glue evenly spread on the surface; 90 patients had osteosarcoma lung metastasis, among them, including 80 patients receiving wedge resection of lung tumor under thoracoscopy, 10 patients receiving radiofrequency ablation of lung tumor. 150 patients had pulmonary metastasis tumor, to be basically fixed by means of pleura friction. 


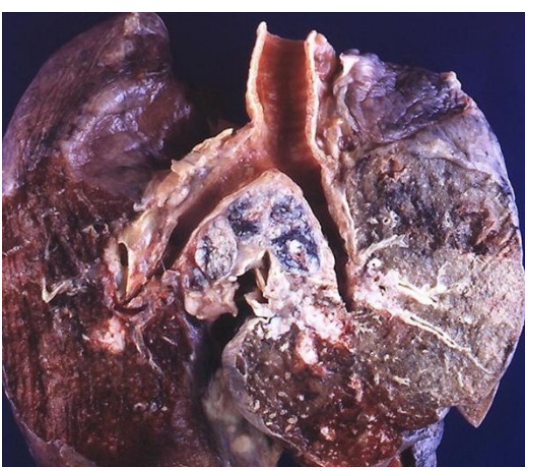

Figure 3. Small cell lung cancer metastasis

The 1900 patients received smooth surgery, with pathological diagnosis clarified, and the surgeries lasted 45-90min. During surgeries, patients' amount of bleeding was $50-280 \mathrm{ml}$, averaging at $150 \mathrm{ml}$; chest tube drainage lasted for 3-8d. After completion of surgeries, 8 patients had mild air leakage which could be healed without special treatment. There was no death in perioperative period. Pathological results after surgery remained substantially consistent with those during surgery. There were 70 patients having nonsmall cell lung cancer, which was treated with excision of cancer specimens. In addition, epidermal growth factor receptor was applied for gene mutation detection. For the remaining patients, radiation pathology as well as chemotherapy can be implemented based on pathology. Such adjuvant therapy was also very important for patients' rehabilitation. 1900 patients received postoperative follow-up examination lasting for 2-49 months. In the follow-up at the 23th months after operation, only 10 patients had osteosarcoma lung metastasis. At the third course of chemotherapy, pneumothorax relapsed, which can be cured by closed thoracic drainage .

\section{DISCUSSION}

From a clinical point of view, secondary spontaneous pneumothorax is a relatively common disorder that occurs primarily in benign lung underlying diseases, such as tuberculosis, lung inflammation and complicated pulmonary emphysema, etc. From medical perspective, secondary lung cancer complicated with spontaneous pneumothorax is extremely rare, whose incidence is only $2 \%$. Both primary disease or secondary diseases are very rare. Because of the above factors, conservative treatment is basically taken for clinical treatment of this disease, but with relatively poor clinical effect obtained; When thoracotomy is applied for patients, because of advanced lung cancer patients' own factors, many patients' physical function can not afford the surgery(LIANG et al., 2010; OFORI-KWAKYE, K et al., 2016) . In recent years, with gradual acceleration of medical technology development pace, the development of VATS is accelerated to some extent. As a result, treatment strategies for the disease are actively carried out, which are expected to be extensively applied in the future. VATS is an advanced diagnose and treatment approach involving TV camera shooting technique and Hightech equipment, which enjoys advantages including minimal injury, less pain, reliable therapeutic effect, and acceptable incision compared with traditional operative methods. VATS is normally conducted by making 3-4 small incisions in diameter of $1.5 \mathrm{~cm}$ on chest wall. With VATS, a doctor can conduct operation with specific instruments while monitoring the screen. This is, the doctor can have more clear sight due to the amplification of thoracoscope and high definition of imaging. Therefore, the operation safety can be greatly enhanced, and the positive rate of biopsy in thoracic lesions can be significantly enhanced compared with aspiration biopsy. VATS provides a new approach for thoracic surgery. Currently, it has been widely used in treating various diseases, and gradually become one of most frequently used methods in thoracic surgery department. For lung cancer complicated with pneumothorax, VATS surgery should be further developed no matter in (see Figure 4 and Figure 5) technique and in operation effect. 


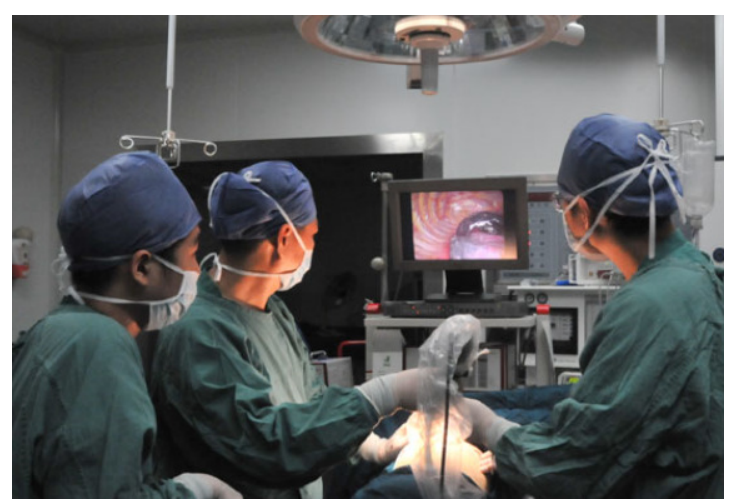

Figure 4. VATS surgical procedure

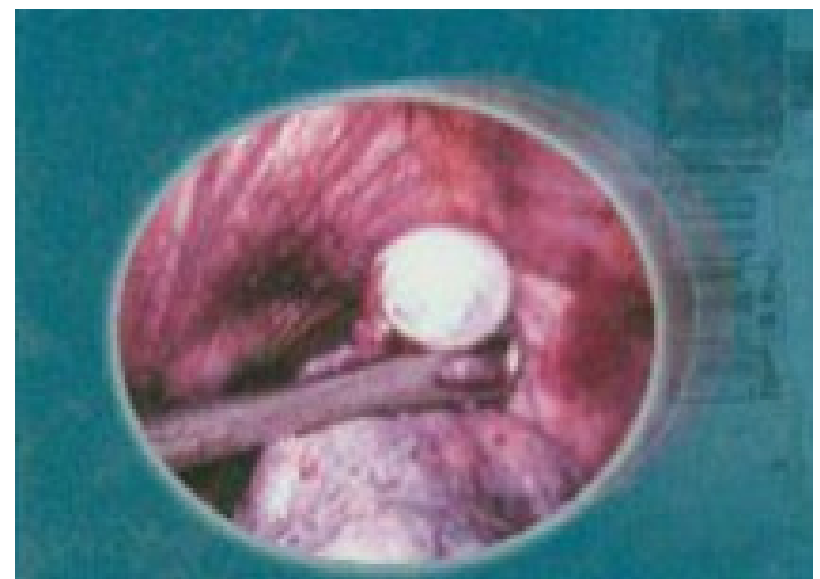

Figure 5. Video-assisted thoracoscopic surgery

According to current situation, for lung cancer patients, there is no reasonable inference for mechanism of spontaneous pneumothorax. These diseases have the following theoretical explanations: first, necrosis lung tumor tissue has spontaneous rupture; second, peripheral lung tumor nodules have airway blockage, then forming ball non-return valve, resulting in excessive expansion of distal lung tissue, and formation of subpleural bullae. Pneumothorax then occur after bullae rupture. Many scholars hold based on research that the mechanism described above belong to one-way valve mechanism; third, for a small number of patients, lung tumor tissue and visceral pleura can have direct invasion (ATTARI et al., 2016; ABDEL et al., 2016). In this study, there were 1900 patients having lung cancer with distal visceral pleura rupture. Without visceral pleura invasion, it belongs to the second mechanism.

For lung tumor complicated with pneumothorax, osteosarcoma lung metastasis is relatively common, followed by other lung metastases, primary pulmonary benign and malignant tumors. Among the 1900 patients in this study, 90 patients had osteosarcoma lung metastasis, and no lung benign tumor occurred. In terms of treatment for this type of pneumothorax, if periphery lung tumor focus is shallow, simultaneous treatment of lung tumor and air leakage is recommended. Treatment of lung cancer complicated with spontaneous pneumothorax is relatively fixed, which is mainly dominant by close drainage or conservative treatment of puncture. However, clinical effect is not satisfactory as patients often have postoperative recurrence. This is mainly because that lung cancer focus is fundamentally incurable. Before patients receive surgery, appropriate surgical approach should be selected based on pathology or patient's own situation.

Typically, diagnosis prior to lung cancer surgery is basically inconsistent with patient's postoperative pathology. In this study, 10 patients had past osteosarcoma cancer which was considered as lung metastasis in preoperative examination but confirmed as primary lung adenocarcinoma by pathology. In the past clinical treatment, CT guidance was basically applied for peripheral lung tumor, followed by needle biopsy of lung to find pathology. However, there are some drawbacks for these techniques in the course of treatment, such as a high incidence of pneumothorax, high false negative rate, suspected needle tumor implant. More importantly, acquisition rate of pathological 
specimens is relatively low, which aggravates pneumothorax to some degree (HAZRA et al., 2015; ALDAHMASH et al., 2016). However, VATS enjoys wide application in clinical practice, which features small trauma and fast recovery, so most patients can afford the surgery. During the surgery, pathological specimens can be intuitively obtained, so that lung cancer treatment measures can be obtained after specimen study.
In summary, lung cancer complicated with spontaneous pneumothorax should be received with sufficient attention. Past conservative treatment is less effective, but application of VATS treatment program can improve clinical outcomes in a way. With small trauma and rapid recovery, patients can receive timely and effective treatment, which avoids continuous diffusion of patient's condition, grasps optimal opportunity for treatment and helps patients discharge early.

RESUMO: o artigo pretende explorar sintomas clínicos e complicações características do câncer de pulmão complicado com pneumotórax, analisar o valor do diagnóstico clínico do VATS e elaborar programas e significados clínicos específicos. Para investigar o diagnóstico e valor terapêutico do VATS para câncer de pulmão complicado com pneumotórax, 1900 casos de pacientes com câncer de pulmão complicado com pneumotórax foram selecionados aleatoriamente como objetos de pesquisa para serem tratados com VATS e, em seguida, foi feita a análise de seus dados clínicos. Os dados clínicos mostraram que muitos pacientes não foram corretamente diagnosticados antes da operação. Na operação VATS, o tecido do tumor pulmonar foi removido e imediatamente congelado e cortado em fatias. A abordagem cirúrgica apropriada foi escolhida com base em circunstâncias específicas dos pacientes. Como pode ser conhecido a partir dos resultados, 1000 casos foram tratados com ressecção em cunha do tumor pulmonar sob toracoscopia, 900 casos foram tratados com cirurgia de incisão pequena assistida sob toracoscopia. 1400 casos de metástases pulmonares foram tratados com fixação de fricção pleural. Todas as operações foram bem-sucedidas, sendo a patologia claramente diagnosticada. Após a cirurgia, 8 pacientes apresentaram vazamento de ar leve, que pode ser curado sem tratamento especial. Não houve morte perioperatória. A análise acima mostra que a VATS pode diagnosticar claramente o tumor pulmonar periférico, e fundamentalmente curar pneumotórax e câncer de pulmão, o que é recomendado na clínica. tratamento

PALAVRAS-CHAVE: VATS. Câncer de pulmão complicado com pneumotórax. Diagnóstico clínico e

\section{REFERENCES}

Abdel, M. S., et al., Design and synthesis of some substituted thiazolo [3,2-a] pyrimidine derivatives of potential biological activities. Saudi Pharm J, 2016. 24: 119-32. https://doi.org/10.1016/j.jsps.2013.12.016

Aldahmash, B. A., El-Nagar D. M., Ibrahim K. E., Attenuation of hepatotoxicity and oxidative stress in diabetes STZ-induced type 1 by biotin in Swiss albino mice. Saudi J Biol Sci, 2016. 23: 311-317. https://doi.org/10.1016/j.sjbs.2015.09.027

Attari, Z., et al., Enhanced ex vivo intestinal absorption of olmesartan medoxomil nanosuspension: Preparation by combinative technology. Saudi Pharm J, 2016. 24: 57-63. https://doi.org/10.1016/j.jsps.2015.03.008

Hazra, M., et al., Designing polymeric microparticulate drug delivery system for hydrophobic drug quercetin. Saudi Pharm J, 2015. 23: 429-36. https://doi.org/10.1016/j.jsps.2015.01.007

Huang H. Z, Li W. T., He X. H., Li G. D., Xu L.C., Wang Y., Application Value of CT-Guided Hook-Wire Localization in Thoracoscopic Resection of Pulmonary Nodules. Oncoradiology, 2013, 04: 309-313.

Liang Z., Liu D. D., Yan T.S., Shen Z. Y., Wang J. D., Wang K. Y., Song J. T., Wang T., VATS Application in Diagnosis and Treatment of Solitary Pulmonary Nodule. Chinese Minimally Invasive Surgery, 2010, 03: 259261 .

Ofori-Kwakye, K., et al., Development and evaluation of natural gum-based extended release matrix tablets of two model drugs of different water solubilities by direct compression. Saudi Pharm J, 2016. 24: 82-91.

https://doi.org/10.1016/j.jsps.2015.03.005 
Wang Z. Q., Lv D. S., Yue S. C., VATS Value in Diagnosis and Treatment of Solitary Pulmonary Nodule. Chinese Journal of Clinical Thoracic and Cardiovascular Surgery, 2013, 05: 607-610.

Ye S. X, Zeng Z. Y., Xu C., Cheng X. J., Chen A.P., Yang S. S., VATS Application in Diagnosis and Treatment of Pulmonary Nodules. Chinese Journal of Clinical Thoracic and Cardiovascular Surgery, 2012, 05: 567-568.

Zhang X. Y, Zhang K., Zhao G. B., Li J. Y., Yan Y. B., Cui J., VATS Application in Diagnosis and Treatment of Lung Cancer Complicated with Pneumothorax. Chinese Journal of Minimally Invasive Surgery, 2011, 08: 704-705, 717. 